Jurnal Akuntansi \& Perpajakan, Volume 2, No. 2, Januari 2021

\title{
PENGARUH PENERAPAN E-SPT TAHUNAN BADAN, TINGKAT PEMAHAMAN PERPAJAKAN DAN KESADARAN WAJIB PAJAK TERHADAP KEPATUHAN WAJIB PAJAK BADAN DALAM MELAPORKAN SPT TAHUNAN BADAN
}

\author{
Trie Nadia Ayu Lizara ${ }^{1}$, Timbul Simangunsong ${ }^{2}$ \\ Sekolah Tinggi Ilmu Ekonomi Jayakarta \\ 1) nadializara310@gmail.com ${ }^{2)}$ timbul_simangunsong@stie.jayakarta.ac.id
}

\begin{abstract}
The Influence of the Implementation of the Annual Entity E-SPT, Understanding Taxation, Tax Awareness Awareness of Taxpayer Compliance of the corporate taxpayers in reporting as the agency annual. In this study using quantitative data types and data sources, namely primary data. Primary data were obtained from questionnaires distributed to corporate taxpayers at random, using the purposive sampling method at the We st Jakarta Middle Tax Office. The number of questionnaires distributed was 100 questionnaires. The results of this study indicate that the Application of the Annual Annual E-SPT of the Agency has a significant effect on taxpayer compliance and taxpayer awareness. While Understanding Taxation has no significant effect on Taxpayer Compliance.
\end{abstract}

Keywords: Implementation of the Annual E-Spt Agency, Understanding Taxation, Taxpayer Awareness.

\begin{abstract}
ABSTRAK
Penelitian ini dilakukan untuk mengetahui Pengaruh Penerapan e-SPT Tahunan Badan, Pemahaman Perpajakan, Kesadaran Wajib Pajak terhadap Kepatuhan Wajib Pajak Badan dalam Melaporkan SPT Tahunan Badan. Dalam penelitian ini menggunakan jenis data kuantitatif dan sumber data yaitu data primer. Data primer diperoleh dari kuesioner yang disebarkan kepada wajib pajak badan secara acak, dengan menggunakan metode purposive sampling di Kantor Pelayanan Pajak Madya Jakarta Barat. Jumlah kuesioner yang disebarkan adalah 100 kuesioner. Hasil penelitian ini menunjukkan bahwa Penerapan E-SPT Tahunan Tahunan Badan berpengaruh signifikan terhadap Kepatuhan Wajib Pajak dan Kesadaran Wajib Pajak. Sedangkan Pemahaman Perpajakan tidak berpangaruh signifikan terhadap Kepatuhan Wajib Pajak.
\end{abstract}

Kata-kata Kunci: Penerapan E-Spt Tahunan Badan, Pemahaman Perpajakan, Kesadaran Wajib Pajak.

\section{PENDAHULUAN}

Pajak adalah kontribusi wajib kepada negara yang terutang oleh orang pribadi atau badan yang bersifat memaksa berdasarkan Undang-Undang, dengan tidak mendapatkan imbalan secara langsung dan digunakan untuk keperluan negara bagi sebesar-besarnya kemakmuran rakyat (UU KUP nomor 28 tahun 2007, pasal 1 , ayat 1 ).

Saat ini, Indonesia bersama dengan 115 anggota negara/yurisidksi 1 yang tergabung dalam komunitas internasional Inclusive Framework on BEPS (Base Erosion and Profit Shifting) tengah mengupayakan terwujudnya 
Jurnal Akuntansi \& Perpajakan, Volume 2, No. 2, Januari 2021

norma pemajakan era ekonomi digital dalam skema revolusi industri 4.0. Pajak sendiri dipergunakan dalam pembiayaan dan infrastruktur negara. Contoh dari infrastruktur negara adalah jalan raya, bandar udara, pelabuhan, listrik, telekomunikasi, air bersih, pengolahan limbah, rumah sakit, sekolah, dan lain sebagainya.

Oleh sebab itu, setiap rakyat wajib membayarkan pajak sesuai dengan aturannya. Yang dikategorikan sebagai wajib pajak yaitu orang pribadi atau badan (subjek pajak), meliputi pembayar pajak, pemotong pajak, dan pemungut pajak, yang mempunyai hak dan kewajiban perpajakan sesuai dengan ketentuan peraturan perundang-undangan perpajakan.

Wajib Pajak Badan yaitu mereka yang memiliki kewajiban perpajakan sebagai pembayar pajak, pemotong atau pemungut pajak, termasuk bentuk usaha tetap dan kontraktor atau operator di bidang usaha hulu minyak dan gas bumi, seperti Perseroan Terbatas (PT), Badan Usaha Milik Negara (BUMN), koperasi, dana pensiun, yayasan dan sebagainya. Di Indonesia, setiap badan wajib mendaftarkan diri dan mempunyai Nomor Pokok Wajib Pajak (NPWP) bagi yang telah memenuhi perysaratan wajib pajak.

Reformasi administrasi perpajakan dilakukan oleh Direktorat Jenderal Pajak (DJP) sebagai bentuk peningkatan kualitas pelayanan perpajakan terhadap wajib pajak dengan dikembangkannya pelaporan pajak terutang dengan menggunakan e-SPT. Penyampaian SPT secara elektonik ini merupakan upaya dari Direktorat Jenderal Pajak (DJP) untuk memberikan kemudahan pelayanan bagi wajib pajak dalam melaporkan jumlah pajak yang harus dibayarkan.

Proses untuk melakukan efisiensi kewajiban pajak melalui sistem e-spt tidak semudah yang dibayangkan, misalnya ada kesulitan yang dialami oleh wajib pajak untuk memasukkan data dokumen perpajakannya karena belum memahami mengenai mekanisme penyampaian dan pengoperasian e-spt. Kesadaran dan kepatuhan subjek pajak diperlukan dalam melakukan mendukung pelaksanaan e-spt untuk melunasi hutang pajaknya dengan baik dan benar.

Beberapa faktor yang mempengaruhi kesadaran wajib pajak dan tingkat pemahaman perpajakan yaitu kurangnya sosialisasi dari pemerintah mengenai peraturan pajak peraturan pajak terbaru maupun program-program pajak terbaru, kurangnya pembinaan kepada wajib pajak, kurangnya merealisaikan program sensus perpajakan nasional yang dapat menjaring potensi pajak yang belum tergali.

\section{KAJIAN LITERATUR}

Bermacam-macam definisi pajak dalam beberapa buku, akan tetap pada hakikatnya memiliki arti dan tujuan yang sama. Pengertian 
Jurnal Akuntansi \& Perpajakan, Volume 2, No. 2, Januari 2021

pajak menurut Mardiasmo (2011: 1), "Pajak adalah iuran rakyat kepada kas negara berdasarkan undang-undang (yang dapat dipaksakan) dengan tiada mendapat jasa timbal (kontraprestasi) yang langsung dapat ditunjukkan dan yang digunakan untuk membayar pengeluaran umum.

Menurut Waluyo (2016: 2), 'Pajak adalah iuran masyarakat kepada negara (yang dipaksakan) yang terutang oleh yang wajib membayarnya menurut peraturan-peraturan umum (undang-undang) dengan tidak mendapat prestasi kembali yang langsung dapat ditunjuk dan yang gunanya adalah untuk membiayai pengeluaran pengeluaran umum berhubung tugas negara untuk menyelenggarakan pemerintahan."

Badan adalah sekumpulan orang atau modal yang merupakan kesatuan baik yang melakukan udaha maupun yang tidak melakukan usaha yang meliputi perseroan terbatas, perseroan komanditer, perseroan lainnya dan badan usaha milik negara atau daerah dengan nama dan dalam bentuk apapun seperti firma, kongsi, koperasi, dana pensiun, persekutuan, perkumpulan, yayasan, organisasi massa, dan bentuk badan lainnya.

Subjek pajak badan adalah badan yang harus melaksanakan kewajiban pajak penghasilan berkenaan dengan penghasilan yang diterima dalam tahun pajak. Subjek pajak badan tersebut dikenai pajak penghasilan apabila menerima penghasilan, jadi kalau tidak menerima penghasilan tidak akan dikenakan pajak penghasilan, apabila sudah mempunyai NPWP hanya mempunyai kewajiban pelaporan pajak saja.

Menurut Ita Ismaya (2018: 2), surat pemberitahuan adalah surat yang oleh wajib pajak digunakan untuk melaporkan perhitungan atau pembayaran pajak, objek pajak atau badan objek pajak, harta dan kewajiban sesuai dengan ketentuan peraturan perundang-undangan perpajakan.

Menurut peraturan Direktur Jenderal Pajak Nomor PER-01/PJ/2017 tentang penyampaian surat pemberitahuan elektronik Direktur Jendral Pajak SPT Elektronik adalah SPT yang disampaikan dalam bentuk dokumen elektronik. SPT Tahunan Elektronik adalah SPT tahunan pajak penghasilan yang disampaikan dalam bentuk dokumen elektronik, baik berupa SPT normal maupun SPT pembetulan. Aplikasi SPT elektronik adalah perangkat lunak yang dapat digunakan untuk membuat SPT elektronik baik yang disediakan oleh Direktorat Jendral Pajak maupun penyedia layanan SPT elektronik.

Pemahaman peraturan perpajakan adalah proses dimana wajib pajak mengetahui tentang perpajakan dan mengaplikasikan pengetahuan itu untuk membayar pajak. Pancawati Hardiningsih (2011: 4) dalam penelitianya menyatakan bahwa meningkatnya pengetahuan perpajakan baik formal dan non formal akan 
Jurnal Akuntansi \& Perpajakan, Volume 2, No. 2, Januari 2021

berdampak postif terhadap kesadaran wajib pajak dalam membayar pajak.

Hal tersebut dapat diambil contoh ketika seorang wajib pajak memahami atau dapat mengerti bagaimana cara membayar pajak badan. Ketika wajib pajak memahami tata cara perpajakan maka dapat pula memahami peraturan perpajakan, dengan begitu dapat meningkatkan pengetahuan serta wawasan terhadap peraturan perpajakan.

Kesadaran merupakan unsur dalam diri manusia untuk memahami realitas dan bagaimana mereka bertindak atau bersikap terhadap realitas. Jatmiko (2006: 26), menjelaskan bahwa kesadaran adalah keadaan mengetahui atau mengerti.

Menurut Jatmiko (2006: 23), "Kesadaran perpajakan seringkali menjadi kendala dalam masalah pengumpulan pajak dari masyarakat. Secara empiris juga telah dibuktikan bahwa makin tinggi kesadaraan perpajakan wajib pajak maka akan makin tinggi tingkat kepatuhan wajib pajak."

Kondisi perpajakan yang menuntut keikut sertaan aktif wajib pajak dalam menyelenggarakan perpajakannya membutuhkan kepatuhan wajib pajak yang tinggi, yaitu kepatuhan dalam pemenuhan kewajiban perpajakan yang sesuai dengan kebenarannya. Menurut Siti Kurnia Rahayu (2013: 5), "Mengungkapkan bahwa kepatuhan perpajakan adalah tindakan wajib pajak dalam pemenuhan kewajiban perpajakannya sesuai dengan ketentuan peraturan perundangundangan dan peraturan pelaksanaan perpajakan yang berlaku dalam suatu negara."

Dalam melaksanakan pemenuhan kewajiban perpajakannya dari tahun ketahun masih menunjukkan presentase yang tidak mengalami peningkatan. Hal ini didasarkan jika kita melihat perbandingan jumlah wajib pajak yang memenuhi syarat patuh di Indonesia sedikit sekali jika dibandingkan dengan jumlah total wajib pajak yang terdaftar.

\section{METODE}

Penelitian ini merupakan penelitian lapangan yakni penelitian yang dilakukan dengan survei langsung ke objek penelitian. Survei yang dilakukan dengan menggunakan alat bantu daftar pernyataan (questioner). Jenis penelitian ini merupakan penelitian kuantitatif yaitu penelitian tentang data yang dikumpulkan dan dinyatakan dalam bentuk angka.

Menurut Sofar Silaen (2018: 69), "Variabel adalah konsep yang mempunyai bermacam-macam nilai atau mempunyai nilai yang bervariasi, yakni suatu sifat, karateristik atau fenomena yang dapat menunjukkan sesuatu untuk dapat diamati atau diukur yang nilainya berbeda-beda atau bervariasi." Dengan demikian terdapat definisi yang jelas dan tepat untuk memberikan pengertian terhadap variabelvariabel yang digunakan. 
Jurnal Akuntansi \& Perpajakan, Volume 2, No. 2, Januari 2021

Dalam penelitian ini data yang diperoleh berasal dari hasil kuesioner yang dibagikan kepada wajib pajak badan secara acak, dengan menggunakan metode purposive sampling. Populasi yang akan digunakan sebagai penelitian adalah wajib pajak badan dengan jumlah infinite. Tujuan dari penelitian deskriptif adalah menghasilkan gambaran akurat tentang sebuah kelompok, menggambarkan mekanisme sebuah proses atau hubungan, memberikan gambaran lengkap baik dalam bentuk verbal atau numerikal.

\section{HASIL DAN PEMBAHASAN}

Pengumpulan data dalam penelitian ini, yaitu pada tanggal 23 Maret 2020 ke kantor wilayah Jakarta Barat untuk mengajukan proposal penelitian kepada KPP yang dituju sebagai tempat penelitian. Kemudian menyusun kuesioner dan menyebarkan kuesioner kepada wajib pajak secara acak sebanyak 100 responden.

Statistik deskriptif memberikan gambaran atau deskripsi suatu data yang dilihat dari nilai rata-rata atau mean, standar deviasi, maksimum, minimum, range, kurtosis dan skewness.

\begin{tabular}{|l|r|r|r|r|r|}
\hline & $\mathrm{N}$ & Minimum & Maximum & Mean & Std. Deviation \\
\hline Perputaran Kas & 24 & 2,00 & 68,00 & 20,0833 & 24,85246 \\
Pertumbuhan & 24 &, 01 &, 24 &, 0919 &, 05496 \\
$\begin{array}{l}\text { Penjualan } \\
\text { Profitabilitas }\end{array}$ & 24 & 6,67 & 65,80 & 19,2187 & 18,54061 \\
ValidN (listwise) & 24 & & & & \\
\hline
\end{tabular}

\section{Tabel 1. Analisa Deskriptif}

1. Penerapan e-SPT Badan: dari hasil output SPSS menunjukkan jumlah responden $(\mathrm{N})$ 100, dari 100 responden nilai Penerapan eSPT Badan terkecil (minimum) adalah 16 dan Penerapan e-SPT Badan terbesar (maksimum) adalah 30. Rata-rata responden yang menjawab setuju dalam pertanyaan terkait dengan Penerapan e-SPT Badan dari 100 responden adalah 23,85 dengan standar deviasi 2,679. Nilai range merupakan selisih nilai maksimum dan minimum yaitu sebesar 14 dan nilai sum merupakan jumlah Penerapan e-SPT Badan dari 100 responden sebesar 2385.

2. Pemahaman Perpajakan: dari hasil output SPSS menunjukkan jumlah responden $(\mathrm{N})$ 100, dari 100 responden nilai pemahaman perpajakan terkecil (minimum) adalah 1 dan pemahaman perpajakan terbesar (maksimum) adalah 5. Rata-rata responden yang menjawab setuju dalam pertanyaan terkait dengan pemahaman perpajakan dari 100 responden adalah 4.07 dengan standar deviasi 0,795. Nilai range merupakan selisih nilai maksimum dan minimum yaitu sebesar 4 dan nilai sum merupakan jumlah pemahaman perpajakan dari 100 responden sebesar 407.

3. Kesadaran Perpajakan: dari hasil output SPSS menunjukkan jumlah responden $(\mathrm{N})$ 100, dari 100 responden nilai kesadaran perpajakan terkecil (minimum) adalah 16 dan kesadaran 
Jurnal Akuntansi \& Perpajakan, Volume 2, No. 2, Januari 2021

perpajakan terbesar (maksimum) adalah 30. Rata-rata responden yang menjawab setuju dalam pertanyaan terkait dengan kesadaran perpajakan dari 100 responden adalah 23,17 dengan standar deviasi 2,764. Nilai range merupakan selisih nilai maksimum dan minimum yaitu sebesar 14 dan nilai sum merupakan jumlah kesadaran perpajakan dari 100 responden sebesar 2764 .

4. Kepatuhan Wajib Pajak: dari hasil output SPSS menunjukkan jumlah responden $(\mathrm{N})$ 100, dari 100 responden nilai kepatuhan wajib pajak terkecil (minimum) adalah 8 dan kepatuhan wajib pajak terbesar (maksimum) adalah 30. Rata-rata responden yang menjawab setuju dalam pertanyaan terkait dengan kepatuhan wajib pajak dari 100 responden adalah 23,39 dengan standar deviasi 2,764. Nilai range merupakan selisih nilai maksimum dan minimum yaitu sebesar 22 dan nilai sum merupakan jumlah kepatuhan wajib pajak dari 100 responden sebesar 2764.

Variabel Perputaran Kas memiliki mean sebesar 20,0833, standar Deviasi 24,85246, nilai minimum sebesar 2,00, dan nilai maksimum sebesar 68,00 dengan jumlah data yang digunakan seluruhnya sebanyak 24 .

Pada pengujian normalitas dengan menggunakan uji Kolmogorov-Smirnov, jika probability value > 0,05 maka Ho diterima (berdistribusi normal) sedangkan jika probability
$<0,05$ maka Ho ditolak (tidak bersistribusi normal).
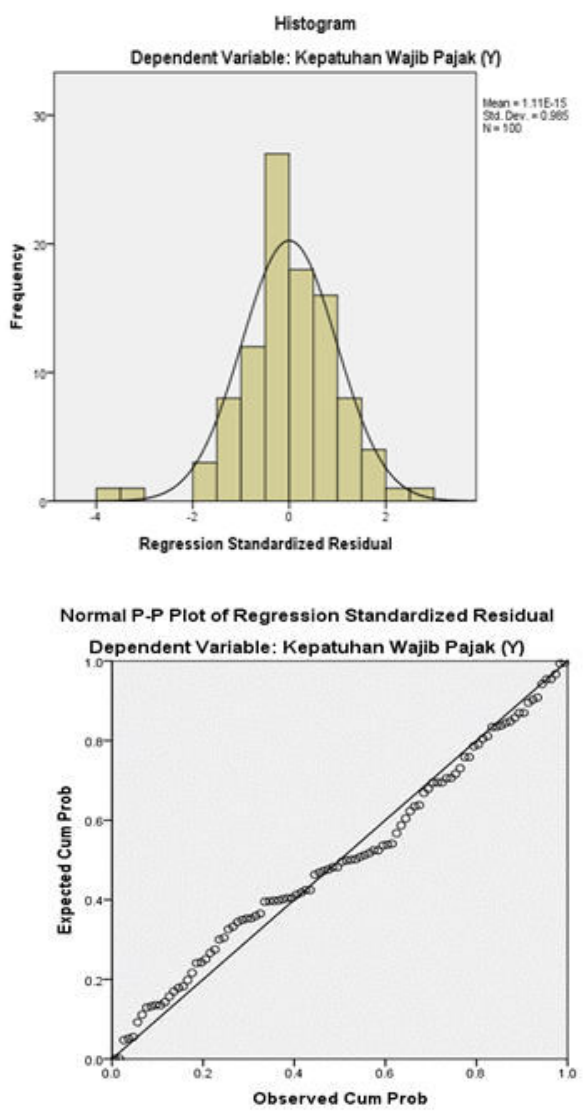

\section{Gamabr 1. Uji Kolmogorov-smirnov}

Pada gambar normal probability plot terlihat sembarang residu berupa dot sebanyak jumlah sampel $=100$ masih berada di sekitar atau tidak jauh dari garis lurus. Hal ini menunjukan distribusi normal.

\begin{tabular}{|c|c|c|c|c|c|c|}
\hline \multicolumn{7}{|c|}{ Coefficients $^{a}$} \\
\hline \multirow[b]{2}{*}{ Model } & & \multicolumn{2}{|c|}{$\begin{array}{l}\text { Unstandardized } \\
\text { Coefficients }\end{array}$} & \multirow{2}{*}{$\begin{array}{c}\text { Standardized } \\
\text { Coefficients } \\
\text { Beta }\end{array}$} & \multirow[b]{2}{*}{$t$} & \multirow[b]{2}{*}{ Sig. } \\
\hline & & B & Std. Error & & & \\
\hline 1 & (Constant) & 2.481 & 2.169 & & 1.144 & .256 \\
\hline & Total_X1 & .228 & .100 & .200 & 2.289 & .024 \\
\hline & Total_X2 & .512 & .306 & .133 & 1.672 & .098 \\
\hline & Total_X3 & .578 & .094 & .523 & 6.163 & .000 \\
\hline
\end{tabular}

Tabel 2. Uji t 
Jurnal Akuntansi \& Perpajakan, Volume 2, No. 2, Januari 2021

Berdasarkan tabel di atas nilai t hitung $=$ 2.289. Nilai $2.289>1,98447$, dengan demikin Ho ditolak dan H1 diterima, berarti Terdapat pengaruh antara variabel Penerapan e-SPT Badan (X1) terhadap Kepatuhan Wajib Pajak (Y). Nilai Probabilitas sebesar 0,000. Nilai 0,000 $<0,05$ berarti Terdapat pengaruh pengaruh antara variabel Penerapan e-SPT Badan (X1) terhadap Kepatuhan Wajib Pajak (Y).

Hasil penelitian juga menyatakan nilai $\mathrm{t}$ hitung $=1,672$ nilai $1,672<1,98447$, dengan demikin maka Ho diterima $\mathrm{H} 2$ ditolak, berarti tidak terdapat pengaruh variabel Pemahaman Perpajakan (X2) terhadap Kepatuhan Wajib Pajak (Y). Nilai Probabilitas sebesar 0,000. Nilai $0,000>0,05$ berarti tidak terdapat pengaruh pengaruh antara variabel Pemahaman Perpajakan (X1) terhadap Kepatuhan Wajib Pajak (Y).

\begin{tabular}{|c|c|c|c|c|c|c|}
\hline \multicolumn{7}{|c|}{ ANOVA $^{\mathrm{a}}$} \\
\hline \multicolumn{2}{|c|}{ Model } & Sum of Squares & df & Mean Square & $\mathrm{F}$ & Sig. \\
\hline \multirow[t]{3}{*}{1} & Regression & 473.890 & 3 & 157.963 & 33.857 & $.000^{b}$ \\
\hline & Residual & 447.900 & 96 & 4.666 & & \\
\hline & Total & 921.790 & 99 & & & \\
\hline \multicolumn{7}{|c|}{ a. Dependent Variable: Kepatuhan Wajib Pajak $(\gamma)$} \\
\hline \multicolumn{7}{|c|}{$\begin{array}{l}\text { b. Predictors: (Constant), Kesadaran Wajib Pajak (X3), Pemahaman Perpajakan (X2), } \\
\text { Penerapan Perpajakan (X1) }\end{array}$} \\
\hline
\end{tabular}

\section{Tabel 3. Uji F}

Berdasarkan tabel di atas nilai $\mathrm{F}$ hitung = 33,857 . Nilai $33,857>2,699$ dengan demikin Ho ditolak dan $\mathrm{H} 3$ diterima, berarti terdapat pengaruh antara pengaruh antara Penerapan eSPT Badan (X1), Pemahaman Perpajakan (X2) dan Kesadaran Wajib Pajak (X3) secara simultan terhadap Kepatuhan Wajib Pajak (Y). Nilai
Probailitas sebesar 0,000. Nilai $0,000<0,05$ berarti terdapat pengaruh antara pengaruh antara Penerapan e-SPT Badan (X1), Pemahaman Perpajakan (X2) dan Kesadaran Wajib Pajak (X3) secara simultan terhadap Kepatuhan Wajib Pajak (Y).

\section{PENUTUP \\ Kesimpulan}

Penelitian ini bertujuan untuk mengetahui Pengaruh Penerapan e-SPT Tahunan Badan, Pemahaman perpajakan, Kesadaran Wajib Pajak terhadap Kepatuhan Wajib pajak di Kantor Pelayanan Pajak Madya Jakarta Barat. Penelitian ini dilakukan dengan penyebaran kuesioner menggunakan google drive yang mengasilkan 100 responden. Dalam penelitian ini menggunakan data primer, data primer merupakan data yang didapatkan secara langsung dari responden. Kesimpulan dari hasil penelitian ini yaitu:Tidak terdapat pengaruh signifikan antara perputaran kas terhadap profitabilitas. Hal ini dibuktikan dari hasil penelitian:

1. Penerapan e-SPT Tahunan Badan berpengaruh terhadap Kepatuhan Wajib Pajak di KPP Madya Jakarta Barat.

2. Pengaruh Tingkat Pemahaman Perpajakan (X2) terhadap Kepatuhan Wajib Pajak (Y) di KPP Madya Jakarta Barat.

3. Pengaruh Kesadaran Wajib Pajak (X3) terhadap Kepatuhan Wajib Pajak (Y) di KPP Madya Jakarta Barat. 
Jurnal Akuntansi \& Perpajakan, Volume 2, No. 2, Januari 2021

4. Pengaruh Penerapan e-SPT Badan (X1), Tingkat Pemahaman Perpajakan (X2), dan Kesadaran Wajib Pajak (X3) secara simultan berpengaruh terhadap Kepatuhan Wajib Pajak (Y) di KPP Madya Jakarta Barat.

\section{Saran}

Berdasarkan kesimpulan pada penelitian ini, terdapat beberapa saran yang perlu disampaikan untuk memperbaiki penelitian selanjutnya yaitu:

1. Sebaiknya DJP lebih banyak mengadakan sosialisasi tentang perpajakan, agar setiap wajib pajak mengetahui dan memahmi pentingnya membayar pajak bagi negara.

2. Diharapkan bagi wajib pajak badan memahami dan mentaati aturan yang sudah di tentukan oleh Direktorat Jendral Pajak (DJP).

3. Kantor Pelayanan Pajak (KPP) harusnya memberikan kemudahan dalam pengambilan data sebagai bahan untuk penelitian guna kebutuhan skripsi.

4. Diharapkan untuk peneliti selanjutnya dapat menemui responden secara langsung, agar responden dapat bertanya ketika terdapat pertanyaan yang kurang dipahami.

5. Penulis berharap untuk penelitian selanjutnya, pertanyaan dalam kuesinoer haruslah lebih banyak dan mendetail.

\section{DAFTAR PUSTAKA}

Agus, Jatmiko. 2006. "Pengaruh Sikap Wajib Pajak pada Pelaksanaan Sanksi Denda, Pelayanan Fiskus, dan Kesadaran Perpajakan Terhadap Kepatuhan Wajib Pajak Studi Empiris terhadap Wajib Pajak Orang Pribadi”. Semarang: Universitas Siponegoro. Tesis Magister Akuntansi

Akmis, Hari Nugroho. 2016. "Pengaruh Kecerdasan Intelektual (IQ), Kecerdasan Emosional (EQ), Kecerdasan Spiritual (SQ) Terhadap Kinerja Pegawai Inspektorat Provinsi Kalimantan Selatan. Banjarmasin: Universitas Lambung Mangkurat

Annisa, Pramudya Nur. 2017. "Pengaruh Penerapan e-SPT terhadap Kepatuhan Wajib Pajak Badan dalam Melaporkan SPT." Yogyakarta: Universitas Negeri Yogyakarta.

Aprilia Afrianti, Timbul.2020 "Pengaruh Pengetahuan Pajak, Kesadaran Wajib Pajak dan Sanksi Pajak Terhadap Kepatuhan Wajib Pajak Kendaraan Bermotor (Studi Kasus di Kantor Sasmsat Jakarta Utara)" Volume 4, No. 1, Februari "2020". Jakarta: Sekolah Tinggi Ilmu Ekonomi Jayakarta.

Ariska Noviyanti, Saprudin.2020 "Pengaruh Sanksi Perpajakan, Tarif Pajak dan Penerapan E-Ffilling Terhadap Kepatuhan Wajib Pajak Orang Pribadi (Studi Kasus di KPP Cempaka Putih) "Volume 4, No. 1, Februari “2020”. Jakarta: Sekolah Tinggi Ilmu Ekonomi Jayakarta.

Darmasi, Hamid. 2014. Metode Penelitian Pendidikan Sosial. Bandung: Alfabeta.

Diana, Sari. 2013. Konsep Dasar Perpajakan. Bandung: PT Rafika Aditama.

Ghazali, Iman. 2016. Aplikasi Analisis Multivariable Dengan Program IBM SPSS 23 (Edisi 8). Semarang: Badan Penerbit Universitas Diponegoro.

Ghozali, Iman. 2011. Aplikasi analisis multivariate dengan program SPSS. Semarang: Badan penerbit Universitas Dipoegoro.

Hardiningsih, Pancawati. 2011. Faktor-faktor yang mempengaruhi Kemauan Membayar Pajak. Semarang: Universitas Stikubank Semarang. 
Jurnal Akuntansi \& Perpajakan, Volume 2, No. 2, Januari 2021

Ita Ismaya.2018. "Pengaruh Penerapan E-SPT Tahunan Badan, Tingkat Pemahaman Perpajakan dan Kesadaran Wajib Pajak Terhadap Kepatuhan Wajib Pajak (Studi Kasus KPP Pratama Jakarta Kemayoran.” Jakarta: Sekolah Tinggi Ilmu Ekonomi Rawamangun.

kementrian keuangan republik Indonesia Direktorat Jenderal Pajak Peraturan Jenderal Pajak Nomor Per03/Pj/2015 tentang penyampaian e-SPT.

Manik, Asri Wuri. 2009. "Pengaruh Kualitas Pelayanan, Biaya Kepatuhan Pajak, dan Kesadaran Wajib Pajak pada Kepatuhan Pelaporan Wajib Pajak Badan yang Terdaftar di KPP Madya Denpasar." Denpasar: Univerisas Udayana.

Mardiasmo. 2011. Perpajakan Edisi Terbaru 2016. Yogyakarta: Andi. mengenai tata cara penyampaian surat pemberitahuan dalam bentuk elektronik.

Peratran Direktorat Jenderal Pajak (DJP) nomor 6/PJ/2009 pasal 1

peraturan Direktur Jenderal Pajak Nomor PER-01/PJ/2017 tentang penyampaian surat pemberitahuan elektronik Direktur Jendral Pajak SPT Elektronik

Rahayu, Siti Kurnia. 2013. Perpajakan Indonesia. Yogyakarta: Graha Ilmu.

Sabil. 2018. "Pengaruh E-Spt Pajak Penghasilan Dan Pemahaman Pajak Terhadap Kepatuhan Wajib Pajak." Volume 2, No. 2, "2018”. Jakarta : BSI Jakarta.

Saidi, Djafar. 2010. Pembaruan Hukum Pajak-Edisi Revisi. Jakarta: Raja Grafindo Persada.

Sigit, Soehardi .2003. Esensi Perilaku Orgaisasi. Yogyakarta: Lukman Offset.

Silaen, Sofar. 2018. Metodologi Penelitian Sosial untuk Penulisan Skripsi dan Tesis. Jakarta: In Media.

Soemitro, Rachmat \& Dewi Kania Sugharti 2010. Asas dan Perpajakan. Bandung: Rafika Aditama.

Sugiyono. 2009. Metode Penelitian Kuantitatif, Kualitatif, dan R\&D. Bandung: Alfabeta.
Surini. 2016. "Pengaruh e-Registration, e-SPT dan eFiling terhadap Kepatuhan Wajib Pajak". Bandung: STIE STEMBI.

Undang-undang Republik Indonesia Nomor 36 tahun 2008 Tentang Pajak Pengahasilan.

Waluyo. 2016. Akuntansi Pajak. Jakarta: Salemba Empat.

Widayati. 2010. "Faktor-faktor yang mempengaruhi kemauan untuk membayar pajak wajib pajak orang pribadi yang melakukan pekerjaan bebas (Studi Kasus pada KPP Pratama Semarang Candisari." SNA XIIII Purwokerto

Zamzami, Faiz dan Nabella Duta Nusa. 2017. Akuntansi Pengantar I. Yogyakarta: UGM Press.

Zuldafrial. 2012. Penelitan Kualitatif. Surakarta: Yuma Pustaka. 